\title{
Cost-Reduction Theory as Legitimation
}

\section{Duncan Kennedy $\dagger$}

I'm going to comment on Bob Clark's piece from a particular point of view, one that's been mentioned implicitly a lot in the last three days, but that may need naming. Several of us here are part of the critical legal studies movement-Morty Horwitz, Bob Gordon, Paul Brest, Mark Tushnet, and Alan Freeman, just to mention those who have been part of the formal proceedings. George Fletcher says he would see himself as one of us were it not for our insistence that our methodology is linked, however obscurely, to our left politics. We're trying to do radical legal scholarship.

$I$ also have a more personal angle that influences what $I$ have to say about Clark's paper. Yesterday afternoon I took a half hour's walk through the neighborhood where I lived with my wife and two small children when I was going to law school here. I went out Hillhouse Avenue, ogling the Italianate and Victorian houses (those Yale didn't tear down in the '50s) of the bourgeois lords of nineteenth-century New Haven, moved by the houses and their suggestion of what was good about that mode of family, noting that even more of them have been turned into offices for the Yale Department of Statistics. Then I walked up the hill to the Kline Biology Tower, beautiful in its brutal reduction of classical motifs, but evocative still, for me, of German and Italian fascist architecture-horrible as well as beautiful. Then down the hill toward the Colt, Winchester factory (the gun that won the West), owned by Olin Mathieson Chemical Corporation, looking out over the railroad tracks to the all-black Elm Haven public housing project, falling down now, ugly and dehumanized from the day it was built. I turned left on Winchester Avenue, where speculators blockbusted the life savings of white working-class families into nothingness and black families moved in with mortgage payments they could never meet. There was a lot of trash in the yards. I was nervous until I'd passed three young black men hanging out, at 3 p.m., in front of the liquor store I used to frequent. Our landlady's name is still on the door of the wood frame house we lived in. She was a mean, bitter, lonely type, an educated, very intelligent, upper-middleclass woman who kicked her husband out and then settled for the best she could get: thirty years in a genteel clerical job at Yale. Then

$\dagger$ Professor of Law, Harvard University. 
around the bend and back in this area, Saarinen's hockey rink, which a crazy sectarian bombed in the spring of 1970, during the trial of Bobby Seale.

This does not lead up to saying that the Symposium is a narcissistic irrelevance, or that Bob Clark should abandon big-business law for legal-services practice. It is just a longer version of the obligatory three-sentence call for the reconstitution of society that John Ely mentioned yesterday. ${ }^{1}$ That and something else: legal scholarship is one of the things that creates the world I've just described-creates it, sustains it, legitimates it. That is not necessarily so, or even intentionally so. Bob Clark's paper is an exercise in legitimating, but he might do scholarship that would point in another direction, a direction more in accord with his own real intentions.

He proposes that we make legal scholarship, particularly historical scholarship, more like the natural sciences, that we concentrate on formulating and then testing falsifiable, law-like generalizations about social life. I tend to think that's a good idea, though I might say it differently. I want my assertions about what happened in nineteenthcentury legal thought to have enough clarity and specificity for someone to be able to knock them down with a piece of evidence that doesn't fit. Beyond that, Clark's methodological homilies seem obvious in the way of canons on statutes. I see that part of his paper as harmless.

I'm much more enthusiastic about Clark's historical typologies and stage theories. These may turn out to be highly valuable. I say "may" because everything turns on the more detailed evidence, and I haven't seen that. My reservations are about what Clark calls "an apparently general pattern of change," which links his various particular studies. I'll spend the rest of my comment on that aspect.

The pattern is indeed very general. Clark asserts that "external" factors such as technology create situations in which a legal change would "reduce costs or disutilities of certain kinds." Those legal changes that reduce the costs or disutilities occur. The new legal institution then creates its own costs, and "substantial legal activity occurs-resulting in statutes, regulations, and case law-in an apparent attempt to [reduce costs], or at least with that objective result." 2 The analogy is to natural selection.

1. John Ely commented on Brest, The Fundamental Rights Controversy: The Essential Contradictions of Normative Constitutional Scholarship, 90 YALE L.J. 1063 (1981), on February 13, 1981.

2. Clark, The Interdisciplinary Study of Legal Evolution, 90 YALE L.J. 1238, 1241 (1981). 
Clark identifies a second, more particular but nonetheless important, pattern within his more general one. In his discussions of the rise of the corporate legal form and of the elaboration of the tax laws, he suggests that there are two kinds of situations in which legal change can occur. In the context of big, macro-changes such as the invention of a new legal institution, legal actors can reduce costs for everyone, or at least avoid hurting anyone, through their innovation. On the other hand, in working out details of a new institution, problems tend to have only zero-sum solutions, and attempts to resolve them therefore lead to the proliferation and complexification of the legal rules involved.

The two general patterns are worked out in detail in a series of examples, only sketched in this paper. I haven't read the longer studies on which Clark bases the sketches. But he has presented enough material so that I think I know what my objections to the full-scale studies would be. The first has to do with the distinction between changes that benefit everyone, and those that involve zero-sum redistributions among conflicting groups. I doubt that Clark will be able to develop criteria for distinguishing these types of situations, criteria, that is, that will meet his own aspirations to scientific rigor. And I doubt that he will be able to substantiate plausibly his hypothesis that one situation leads to major institutional shifts while the other leads merely to proliferation of the doctrinal underbrush. But I'll leave it at that and move on to the more spiffy subject of the concept of cost or disutility.

Clark's theory of cost-reducing legal change resembles that of George Priest, ${ }^{3}$ but differs from Priest's in that it emphasizes the conscious role of lawyers and judges who innovate in response to costs, rather than the more automatic, superficially mechanical process called relitigation. One way to understand the paper is as an attempt to apply the Calabresi-Posner conception of a cost or disutility to the history of legal change, while cutting down the pretensions of efficiency theories so as to increase their plausibility. That's the point of his distinction between cost reduction and mere squabbling.

Because his work is partly critical, Clark provides an analysis of what can go wrong with cost-reduction theories of change. And because, in spite of the restrictions he imposes, his version seems vulnerable to just the same critique he makes of Priest, I will formulate my comments in his terms. I could equally well have used Bob Gor-

3. See Priest, The Common Law Process and the Selection of Efficient Rules, $6 \mathrm{~J}$. Legal Stud. 65 (1977). 
don's typology of spurious "adaptationist" responses to the problem of historicity (i.e., lawlessness) ${ }^{4}$ or Mario Rizzo's striking demonstration of the vacuous character of Calabresian efficiency analysis. ${ }^{5}$

Before I start, let me say again that I think the concrete, historical, and typological part of Clark's work is likely to be very valuable. I am focusing exclusively on his scientism, which seems an unnecessary weakpoint. First, then, Clark says of Priest's version of the costreduction theory that "its meaning does not seem specific enough to be very interesting or useful." 6 Second, its empirical testability is in doubt." Third, one must wonder about "the importance of the [cost-reduction] effect relative to other influences on legal change."8

First, the meaning of "cost or disutility." In his general, "law-like" formulation of his pattern of change, Clark avoids saying whose cost or disutility is in question. This makes it possible, when dealing with specific instances of change, to manipulate the concept in a way that threatens the meaningfulness of the whole exercise. In some of his examples, it sounds as though "cost" means "social cost," with the implication that all of society would benefit by cost reduction. At other times, it is clear that he means the cost to some specific group.

Supposing that Clark's general intention is to speak of social cost, so that it will be possible to describe a legal change as benefiting everyone rather than simply resolving a situation of zero-sum conflict, Clark says nothing about how the legal scientist is to compare the social-cost-reduction advantages of the numerous alternative legal solutions that are always available to deal with a given legal problem. I will just assert dogmatically that there is no non-controversial, nor even any apolitical, way to formulate the concept of social cost. Depending on which of the various formulations Clark chooses, he will be able to make any one of a number of possible innovations look like the cost-reducing one, and even argue that when no change occurred, it was because all proposed changes would have increased rather than decreased costs.

Clark's second problem with George Priest's early theory, and my second problem with Clark's present views, is that I don't think he'll be able, even with all the will in the world, to offer convincing scientific-style evidence to confirm or disconfirm his theory. In part this is a result of another definitional ambiguity. Sometimes it sounds as

4. Gordon, Historicism in Legal Scholarship, 90 YALE L.J. 1017, 1028-36 (1981).

5. Rizzo, The Mirage of Efficiency, 8 HorstrA L. REv. 641 (1980).

6. Clark, supra note 2, at 1268.

7. See id. at 1268-69.

8. Id. at 1269. 
though he is using something like the tautological neoclassical definition of "utility." For example, he suggests that if merging businesses chose the corporate form, that is evidence that the corporate form reduced costs. But that is good evidence only if we define "utility" so that everyone always does what they do in order to maximize utility. If Clark is not using a tautological definition, then I'd like to hear him formulate some other possible explanation of the choice of the corporate form, and then present some evidence that the nontautological cost-reduction hypothesis is more plausible than the alternatives.

There is also an opposite problem. Sometimes Clark suggests that his hypothesis is indeed extremely specific: businessmen and people involved in the legal system have an idea of cost, which they formulate just as he is formulating it, and they set out consciously, as evidenced by their books, articles, letters, and reported conversations, to reduce those costs. But in this version, it is difficult to see what the law-like generalization will be, other than that people tend to act so as to bring about results that seem to them desirable given their perceptions of the possibilities of the situation. You don't need an apple hitting you on the head to come up with that one.

Yet a third notion is that we can equate "cost reduction" with "profit maximization." Then, if we could say that firms that adopted a particular legal form or device were more profitable than firms that did not, we might also expect that the legal device would flourish because profitable firms may be more likely to survive than unprofitable ones, other things being equal. I don't think this will turn out to be a fruitful line of inquiry, supposing always that we are looking for law-like generalizations with the simplicity and power of (some of) those of the natural sciences.

To take a problem almost at random from a dozen one could think of, what of legal innovations that work because they create costs for others, rather than reduce them? And what about dumb, counterproductive legal innovations that survived because they found favor with law firms whose clients were so successful that they could afford a lot of legal bungling? Once again, I think Clark is going to have trouble maneuvering between the tautology that "what survived survived because it had survival value," and an infinitely more complex, multi-dimensional analysis that will look like plain old history, and not like science.

Clark's third problem with George Priest's theory is that he suspects that there are influences on legal change other than the reliti- 
gation effect. It may seem odd for me to adopt a similar criticism of cost reduction, as $I$ have been arguing that the very concept is so vague and ill-defined as to be close to useless. But that was an extreme statement, law-professor-like in its snooty and dismissive tone, and I would like now to retract it. I think it is sometimes useful, in order to understand the past, if not in order to formulate scientific law-like generalizations, to analyze the impact of legal change on what some people perceived as bad or good for them. In particular, it often seems a good idea to look at how the ruling class looks after what it conceives as its interests-at what the whole ruling class, for all its internal divisions and conflicts, takes as elemental.

That much is just common sense. But because it's just common sense, it's not likely to provide an explanation of legal change that has the conversation-stopping logical-positivist finality Clark is looking for. After we've found out what the actors wanted, and gotten some idea of the extent to which the objective circumstances promoted or impeded their achieving their goals, we'll want to take into account some other things as well. In particular, we'll want to get some idea of the various ways in which they might have but did not conceptualize the situation.

This problem of alternative ways in which historical actors might have seen a situation is important on two levels. First, let's take for granted that they had to want what they wanted, that is, that their conception of cost or disutility was just there as a datum of nature. There is still the question of how they chose among the various strategies of cost reduction that are always available.

Part of the answer to this will lie in the limited character of the available repertoire of concepts for conceiving cost-reduction strategies. In his paper, Clark mentions Bob Gordon's work on late nineteenthcentury bankruptcy. ${ }^{9}$ In that work, Gordon shows that a particular pattern of legal change can be plausibly explained as the adaptation to a new field of a style of legal reasoning that was already dominant in constitutional law and in some areas of private law. An account of the development of bankruptcy law that ignored this similarity would be seriously misleading.

The notion of alternative conceptions applies as well to the definition of cost itself, to what is to be minimized as well as to the means for minimizing. Bob Gordon pointed this out in his paper. ${ }^{10}$ It's not

9. Id. at 1254 n.26; see R. Gordon, Approaches to the Study of Legal Thought and Legal Practice in Late 19th Century America (April 1980) (unpublished paper delivered at a Harvard Law School Seminar on Basic Legal Research).

10. See Gordon, supra note 4 , at $1034-35$. 
much of an explanation of legal change to say that people minimized costs if it is then open to ask why people see $x$ and $y$ as disutilities and $z$ as a positive benefit. Even the conventional wisdom is that definitions of what events are costs, and what events are benefits, vary from culture to culture and from time to time within a given culture. If one chooses to say that this is outside the scope of the naturalscientific enterprise we are engaged in, then you're reduced to a law that says that people try to accomplish whatever their culture tells them is desirable at a given moment. If, on the other hand, one takes the tack of saying that there are objective costs that are just plain there, whatever people at the time thought was a cost, then it seems that the whole historical enterprise must await the development of a theory, first, of objective costs, and, second, of how historical actors minimize costs of whose existence they are unaware. Brad Honoroff, in an unpublished paper, elaborates these points in ways that I find altogether convincing, and incidentally argues that the same critique can be made of those versions of orthodox Marxism that insist on a rigid distinction between a material base and a cultural superstructure. ${ }^{11}$

Even if what I've just been saying is right, which is certainly questionable, what's the point of going on about it at such length? Is there anything beyond the sheer joy of trashing to be derived from this kind of critical exercise? I think the answer is yes. Theory of the kind Bob Clark proposes in this paper is an obstacle to the transformation of the world, the world I tried to describe at the beginning of my comment.

First, it is an obstacle because it makes the world as it is look rational and necessary, even just (who can object to "cost reduction"?), as opposed to arbitrary and contingent. This is a misrepresentation that has an effect: it diverts energy from the job of finding the truths we need to know about the world if we are to be effective in transforming it; it diverts energy from the task of figuring out what the world should be like.

Second, leaving aside the political issue, Bob Clark is making quite big claims. If it were possible to achieve the results that he's after as easily as his paper suggests, then it would obviously be a good idea for radicals, as well as liberals and conservatives, to go after them. The belief that it's that easy to achieve big results is a kind of narcotic. If people get into it, they'll pour energy into scientism-energy that might have been put to use in other places.

11. See B. Honoroff, Magic, Terror, and Narcissism (1979) (unpublished paper) (on file with Yale Law Journal). 
Having said that, I want to make a whole series of qualifications and reservations. These are not minor: people often misinterpret the critical position because qualifications and reservations aren't made explicit. First, if Clark's asserted general pattern of legal change really exists, if he has made a genuine discovery, if he is on to a truth about the development of law, then it is irrelevant that the truth will be an obstacle to left transformative activity. If this view is true, then the fact that the truth is an obstacle is just tough luck. The world is full of truths that are obstacles; indeed, most of what we find out from day to day about how things work suggests that it is incredibly difficult to make things different than they are. If Clark has made a valid addition to the catalog of our liabilities, then we should thank him, no matter how sad we may be to hear the bad news. But, as I've already said, I think the proposed general pattern doesn't exist.

Second, I haven't shown in this comment, and none of the other critical commentators have shown in theirs, that it is impossible to produce a theory that (a) would be true and (b) would powerfully suggest that the way the world is on Winchester Avenue is rational, necessary, and even just, not to speak of its efficiency. I just don't think that Bob Clark, or the other liberal legal scholars working to render the liberal legal universe intelligible in terms of these values, are succeeding. Maybe it's because they're attempting the impossibleI sure hope so. It would be a bummer if Bruce Ackerman actually succeeded in establishing a set of irrefutably rational and just criteria that showed that eighty percent of everything $I$ hate about the world just has to stay that way. It would be a bummer, but it might happen. It hasn't happened yet.

Third, I don't think there's any big difference in principle between what we in the critical movement do and what scholars like Bob Clark do, if we look at it in terms of "the nature of truth." We try to show, just as he does, that there are patterns to legal change in the past. In my own work, I appeal to the same kind of evidence that Clark does, and I come up against all the same difficulties. My assertions about the legitimating function of liberal legal thought, and about the way pre-rational or a-rational structures of thought mold legal development, may all turn out to be wrong, using the same critical criteria I've been trying to apply to Clark. In that case, my work goes right down the chute.

Fourth, the critique of liberal legalism is only a small contribution to a valid strategy of legal leftism. (a) The belief in false theories of the evolutionist or cost-oriented kind does not cause people to be conservative,-and the critique of such theories cannot all by itself have 
any substantial impact on anybody's politics. (b) People do not hold to theories of the kinds I have been criticizing simply because they serve conservative ends. At least some people believe in them because they think they're true, even though it seems to them too bad that they are true. (c) For a lot of people, legitimating theories, theories that show the rationality, necessity, and (often) efficiency of things as they are, serve as a kind of defense mechanism. These theories are a way of denying, of avoiding, of closing one's eyes to the horribleness of things as they are. They lessen the pain.

Attacking this kind of theory, if I'm right in my defense-mechanism analogy, may have some political use, even though my mode of attack couldn't be less therapeutic. If we could really smash the defense mechanism, we'd liberate some energy, according to the basic psychiatric version of the psyche. People often tell me that liberating energy can be good or bad, and that a loss of faith in liberal legalism is most likely to lead to reaction. Hitler and Stalin are offered as good examples of people who just hadn't been convinced of the virtues of liberalism. If we are making it harder to believe in liberalism, then we're making it easier to believe in, or even to be, Hitler or Stalin.

I think it's just Bickelian silliness to believe that the critique of liberalism produced Hitler or Stalin, but I'm happy to concede that you don't go around attacking people's defense mechanisms, even ineffectually, unless you have at least an intuition that the energy you might liberate will flow in a good direction. It's an empirical question. In the case of this group, my intuition about the facts is that the work of critique doesn't lead people to move to the right, but to the left. If the defensive maneuvers dissolve, people begin to address more real questions.

But what, you are so quick to ask, is more real than scientism? Three things. First, we should devote our energies to actions in the here-andnow: short-term, relatively opportunistic, acting-out kinds of actions. For example, there ought to be more women and more blacks on the Yale faculty. There were almost none when $I$ was a student, and ten years later there are still almost none. People should hassle, harass, demonstrate, and sit in against the Yale faculty until it mends its ways. Second, we need information about why things are the way they are that isn't oriented to showing that the real explanation is that they have to be that way. And finally, we need utopian speculation. We need to spend time not on scientism but on dreaming up the ways we think things might be better than they are. Utopian speculation is in some ways the hardest to come by. What would we do with power, anyway? 